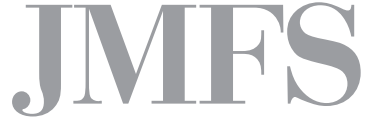

Journal of Management and Financial Sciences
Volume XI

Issue 34 (November 2018)

pp. $23-49$

Warsaw School of Economics

Collegium of Management and Finance

Piotr Zaborek

Institute of International Marketing and Management

SGH Warsaw School of Economics

\title{
Strategic orientation, CSR and operational performance: Mediation and moderation effects in the Polish food-manufacturing industry
}

\section{ABSTRACT}

The aim of the study is to investigate relationships between strategic orientation (SO), involvement in corporate social responsibility (CSR) and operational performance (OP). It tests the proposition that $\mathrm{SO}$ is not linked with OP directly but through CSR serving as the mediator. In addition, SO is hypothesized to moderate the association between CSR and OP. The research involves a representative cross-sectional survey of 400 managers of SMEs operating in the Polish food manufacturing industry. Statistical methods include confirmatory factor analysis with AMOS 24 and multiple linear regression using SPSS 24.

The study reveals a complete mediation effect by CSR of the links from three aspects of SO to OP. Specifically, aggressiveness, proactiveness and defensiveness are positively associated with CSR, while analysis, future orientation and risk propensity show no relationship. Also, aggressiveness moderates the link from CSR to OP, so that firms with higher aggressiveness display a stronger connection between CSR and OP.

The outcomes suggest that part of the positive effects of CSR may come from more general strategic stances and attitudes. Moreover, it seems that certain aspects of strategic orientation might be more effective when implemented in an organizational environment with strong CSR values. In particular, strategies based on aggressiveness and proactiveness appear to be more effective when complemented by heightened social sensitivity.

This research validates the role of CSR as a viable managerial approach contributing to greater operational performance of companies. This could help build a stronger case to promote socially responsible business practices not only through its beneficial social impacts but also due to its effects 
on firms' performance. To the author's knowledge, this is the first research focused on associations between SO, CSR and OP, using a large, representative sample of SMEs.

Keywords: CSR, strategic orientation, performance, manufacturing, survey JEL Classification Codes: M10, M14

\section{Introduction}

The main objective of the study was to investigate the role of strategic orientation (SO) as an antecedent of CSR involvement. The SO concept is defined as "organizational principles that direct and influence the activities of an organization" [Hakala, 2011]. Strategic orientation can be looked at as the part of organizational culture that determines how a company addresses its market challenges. Based on dominant profiles of SO, a popular and longstanding typology distinguishes four types of companies: prospectors, defenders, analyzers and reactors [Miles and Snow, 1978]. From the perspective of sustainable management, it can be argued that strategic orientations emphasizing performance (e.g. prospectors) may be unlikely to induce in their members (employees) attentiveness to the needs of other stakeholders (e.g. local communities, other employees). By the same token, their leaders may not find it essential for the company's success to follow the principles of CSR. Consequently, strategic orientation could be a meaningful factor in a company's stance on sustainability and social responsibility. That was the main assumption underlying this investigation of the relationship between SO and CSR. In several previous works, involvement in CSR was hypothesized to rely on a more general strategic position of a company. The rationale for such a proposition is grounded in the belief that even carefully thought-out strategies need special conditions and additional competencies to be transformed into positive operational and financial effects. One of such competencies could be CSR, which can induce - among other things - a higher level of involvement and loyalty from employees, leading to a more productive and responsive organizational culture. A few prominent examples of previous studies on the topic include works by Maignan et al. [1999], Qu [2009], Galbreath [2010] and Torgusa et al. [2012, 2013]. These authors found evidence (although often inconclusive) for links between aspects of SO, CSR and company performance, suggesting that CSR could serve as a mediating factor leading (in certain circumstances) to improved performance. However, these and other studies were not without limitations, often based on narrowly defined populations (e.g. star-rated hotels in China or members of the American Marketing Association), including small sample sizes and incomplete operationalizations of SO and CSR. This points to a research gap that could be addressed by the current study.

This paper is structured as follows. First, it looks at the concept of CSR and the past research that links CSR to a company's performance. Then it overviews the literature on strategic 
orientation and its interplay with CSR. Next, the paper presents the conceptual model and research hypotheses, and proceeds to discuss research methods, including the sample and population, measurement scales and statistical analysis. Presentation of the findings comes next and the paper wraps up with conclusions, limitations and suggestions for further research.

\section{CSR and corporate performance in past research}

The understanding of CSR employed in this paper is in keeping with the mainstream tradition of the triple bottom line that identifies three groups of objectives with corresponding activities: economic, social and ecological [Peñaloza, Mish, 2011]. As such, this study distinguishes the following dimensions of the CSR involvement: (1) market policies (entailing a conscientious attitude in interactions with suppliers, customers, and other supply chain partners); (2) local impacts (communication, cooperation, and support for local and wider social partners); (3) natural environment (commitment to running business operations with the smallest possible negative impacts on the environment); and (4) employee relations (all corporate socially responsible activities aimed at employees).

The academic interest in costs and benefits of CSR for business has been high over the past several decades resulting in many publications on the topic. Nevertheless, the existing literature on CSR does not provide unequivocal and conclusive evidence on how operational and financial performance can be affected by implementing responsible business practices [Tang et al., 2012]. Indeed, the scale of interest and confusion surrounding the topic is aptly illustrated by Lu et al. [2014], who meta-analyzed 84 papers published between $2002-2011$ that explored this relationship and found a wide - often inconsistent - array of conceptualizations, methodological approaches and outcomes. Even though the majority of authors lean towards the opinion that CSR involvement is frequently advantageous to companies, the number of the benefits ascribed to CSR varies widely and the understanding of the nature of the mechanisms that could lead to those benefits is often vague. This topic is particularly poorly investigated for small and medium-sized businesses. From a theoretical standpoint, there are compelling arguments for a positive link between CSR and performance. For one, stakeholder theory implies that firms that effectively respond to the needs of various groups of individuals are likely to enjoy improved relationships with customers, employees, shareholders and business partners [McWilliams et al., 2006].

Additional insights are offered by transaction cost economics, which suggests that companies with a poor social responsibility image will have higher transactional costs due to so-called "more expensive explicit claims", such as lawsuits and fines from the government, demands of shorter payment periods from suppliers and higher costs of obtaining capital owing to the increased risk perception by banks and investors [Peloza, 2006]. According to the resource-based view, CSR can be counted among intangible strategic resources, which - when rare and not easily substitutable - may contribute markedly to competitive advantage [Luo, 
Bhattacharaya, 2006]. Examples of intangible assets that can be augmented by CSR are brand names, company reputation and better skills of employees and managers. In contrast, some scholars do not approve of firms getting involved in CSR, since they believe that whatever benefits can be gained this way are canceled out by high costs of CSR programmes; that is, firms face a direct trade-off between social and financial performance. This view holds that to carry out CSR policies, businesses frequently bear costs that put them at an economic disadvantage compared to other, less socially involved companies [Auppele et al., 1985].

Although the current consensus in economic theory is that with socially responsible management the balance of costs and benefits for a company is likely to be positive, empirical research seems to paint a more varied picture - reported findings have ranged from negative, to neutral, to clearly positive relationships between CSR and performance. Detrimental effects of CSR were found by Wagner et al. [2002], who studied the European paper manufacturing industry and noted that environmental investments were negatively correlated with financial performance. However, the companies that were investigated were forced to make those investments by mandatory legal regulations, so they were reactive and hence could entail different causal mechanisms and effects.

Marginally positive or neutral financial effects were reported in a number of studies, more frequently in longitudinal research then cross-sectional projects. For example, Nelling and Webb [2009] found CSR to be positively associated with performance only in cross-sectional analyses repeated separately for subsequent years, but the same data processed with a longitudinal approach returned a much weaker relationship. The only hint of a causal relationship was identified between the stock market performance of the companies and expenditures on employee related CSR programmes. This prompted the authors to speculate that companies, having succeeded on the stock exchange, were inclined to increase their CSR spending on employees, implying that CSR was not a cause but rather an effect of high performance; a way to reward employees for the company's success. The lack of a link between CSR and performance was reported by Bello [2005], in the analysis of American investment funds in the late $1990 \mathrm{~s}$. His comparison of the funds with only socially responsible firms in their assets to those that build their portfolio according to risk and return considerations, identified no significant differences in profitability: seemingly firms with and without CSR programmes offered similar returns. Matuszczak and Różańska [2017] in a longitudinal study of 18 banks found no evidence of substantive effects (either positive or negative) of the banks' CSR initiatives on metrics of financial performance.

Notwithstanding the above examples, most of the past research did identify some positive effect. One well-cited study revealing positive bottom-line impacts of social responsibility was authored by Torgusa et al. [2012], who investigated 171 Australian SME manufacturers of industrial machinery and equipment. The main finding was a medium strong association between proactive CSR and financial performance. The structural model tested there placed CSR as a mediating variable between three corporate capacities (shared vison, stakeholder management and strategic proactivity) and performance. Despite the authors claims that the 
mediation was confirmed, the model was missing direct regression paths from capacities to performance to ensure that due to mediation from CSR these paths were insignificant. In another article, using the same data set, Torgusa et al. [2013] found an even stronger effect of CSR on financial performance once synergy between three variables were accounted for as interaction terms. The identified synergy entailed stronger correlations between individual dimensions of CSR and performance for higher levels of other CSR dimensions.

A study by Tang et al. [2012] involved analysis of longitudinal data from 130 American enterprises from 1995 to 2007 . The outcomes indicate a positive financial impact if a company introduced CSR gradually, over a long period of time, beginning with internal, employee-oriented dimensions of social responsibility and proceeding outwards. The research seems to highlight the critical role of organizational learning and the need to absorb CSR principles into organizational culture before any benefits can materialize. A lack of a deeply ingrained appreciation among employees for the ethical and socially responsible mindset can lead to failures in implementing CSR programmes aimed at the supply chain, local communities and natural environment.

Examples of other research that offer evidence on positive ties between social responsibility and performance include the papers by Peters and Mullen [2007], Rettab et al. [2009], Wagner [2009] and Zaborek [2014].

The part of CSR research stream that is relatively less popular with scholars but has a fundamental role in developing a better understanding of the CSR-performance link is concerned with identifying and explaining the mechanisms leading from responsible corporate behaviour and attitudes to improved performance. In the earlier mentioned research by Torgusa et al [2011, 2012] and Tang et al. [2012], CSR seemed to work best in organizations that had the right capacities and organizational culture in place, which was discovered by testing statistical models where performance metrics were explained not only by direct connections but also through mediation and moderation between pertinent variables.

In another study, Kang et al. [2016] identified 4 factors underlying a successful implementation of socially responsible practices that they labelled: (1) slack resources, (2) good management, (3) penance, and (4) insurance. Proponents of the slack resources theory investigate direct links between CSR and performance and posit that any positive correlation is due to the availability of excess funds (i.e. slack resources), which encourage managers to develop CSR programmes. In this view, CSR is not a cause of improved performance but an effect, and as such is quite redundant and even harmful for financial success. One early, well known study in this stream of research [McGuire et. al., 1988] shows that CSR expenditures are more closely related to the previous performance than the subsequent one. The good management hypothesis assumes that CSR has a positive influence on finances through intermediate effects, which constitute improvements in various metrics of operational performance, such as employees' attitude, satisfaction and involvement, customer satisfaction and better supply chain relations. Proponents of this approach often develop composite metrics meant to capture the amount of operational improvement, such as the product social performance coefficient, 
which turned out to be positively correlated with CSR on the one hand and profitability on the other, essentially serving as a mediator [Jayachandran et al. 2013]. With the penance mechanism researchers assume that firms get involved in spending on CSR as a compensation for past transgressions (e.g. pollution incidents, bad treatment of employees). Here, CSR serves as a means to internalize external costs due to irresponsible previous decisions. This outlook expects positive ties of CSR with performance, but it is mainly due to avoidance (in part or in full) of retribution by governmental bodies and customers. Researchers who assume the existence of the insurance mechanism expect that firms spend on CSR initiatives to protect themselves against possible future incidents that could harm their reputation, by building good reputation at present [Minor and Morgan, 2011]. This perception of CSR is similar to the earlier view, except the fact that the transgressions against which CSR is supposed to offer safeguards are not in the past but in the future.

More recently, Aluchna [2017], based on a series of 16 depth interviews of CEOs and CSR directors, found that the most important benefit reported by managers was positive CSR impacts on employees, but - interestingly - other benefits were scarce, and the interviewees questioned the effectiveness of including references to CSR in marketing campaigns, judging it as too risky for the credibility of the company, not only among customers but also employees.

Charitable marketing campaigns by large network retailers were discussed by Stefańska and Pilarczyk [2015], who suggest that these initiatives can have underwhelming outcomes on performance due to run-of-the-mill ideas for charitable actions, which make it difficult to stand out from other companies, and deficient communication with stakeholders about the achieved social effects, to show that charitable efforts are not a sham, but they have real impacts on beneficiaries.

\section{Relationship between strategic orientation and CSR in the existing literature}

The objective of the study is to investigate the role of strategic orientation ( $\mathrm{SO}$ ) as an antecedent of CSR involvement. At a general level, the SO concept is defined as "organizational principles that direct and influence the activities of an organization" [Hakala, 2011]. Strategic orientation can be looked at as the part of organizational culture or organizational capacity that determines how a company addresses its market challenges. This cultural understanding of SO is sometimes reflected in the terminology, when the alternative name used for the concept is strategic culture [Johnson et al. 2012]. Within this conceptual framework one could identify widely different approaches to doing business: from highly aggressive and competitive to defensive and reactive. Based on such dominant strategic profiles, a popular and longstanding typology distinguishes four types of companies: prospectors, defenders, analyzers and reactors [Miles and Snow, 1978]. It should be noted that SO is not a uniform construct and, according to some authors, it can subsume more specialized sets of attitudes 
and practices, such as marketing orientation, entrepreneurial orientation and innovative orientation, all of which are cast as types of SO focused on different functional areas of the company [Balodi, 2014].

From the perspective of sustainable management and CSR, it can be argued that those strategic orientations that emphasize performance (e.g. prospectors) may be unlikely to induce in their members (employees) high attentiveness to the needs of other stakeholders (e.g. local communities, other employees). By the same token, their leaders may not find it essential for their company's success to follow the principles of CSR. Consequently, strategic orientation could be a meaningful factor in a company's stance on sustainability and social responsibility. This was the main assumption underlying our investigation of the relationship between SO and CSR. Next, to provide more theoretical context for this research, three salient studies were outlined which looked at similar research problems.

In several previous works, involvement in CSR was hypothesized to rely on a more general strategic position of a company. The rationale for such a proposition is grounded in a belief that even carefully thought-out strategies need special conditions and additional competencies to be transformed into positive operational and financial effects. One of such competencies could be CSR, which can induce - among other things - a higher level of involvement and loyalty from employees, leading to a more productive and responsive organizational culture. Arguably, the first to explore CSR in a mediating role leading to business benefits was the research by Maignan et al. [1999]. There, the authors investigate how the so-called "corporate citizenship" is shaped by aspects of organizational culture and how it in turn affects performance metrics. Corporate citizenship was defined as "the extent to which businesses meet the economic, legal and discretionary responsibilities placed on them by their various stakeholders". Considering that "discretionary responsibilities" involve philanthropic activity and employee-oriented programmes, this concept is similar in meaning to the CSR involvement adopted in the current study. Organizational culture encompassed those factors that - in the authors' view - could encourage managers to actively meet their social responsibilities. Cultural variables included market orientation, competitive orientation and humanistic orientation. Based on the Likert-type measurement items used there, the joint scope of market and competitive orientation was akin to the strategic orientation employed in the current research, in particular its aspects of aggressiveness, defensiveness and analysis. The findings reported in the paper implied that fulfilling social obligations did not come at the expense of diminished profitability; in fact, there was evidence that it could lead to better performance directly as well as through mediators of employee commitment and customer loyalty. As regards reliability and validity of the outcomes, even though the study was designed and implemented carefully and statistical analysis was thorough, there was a shortcoming concerning the sample size and structure. The authors collected data from a rather small group of 229 marketing executives, sourced from a database of members of the American Marketing Association (AMA). Such a sampling frame, it seems, is hardly representative of a larger population of companies, since it could be argued that the AMA brings together select marketing professionals who have 
a keen interest in modern marketing and management practices and are likely to use them in their own companies. Hence, the same effects might not be found in other firms led by individuals less familiar with marketing and management theory, including the concepts of sustainable management and CSR.

In another relevant study, Qu [2009] looked into CSR as an intermediary variable between market orientation and financial performance, finding support for the existence of the full mediation effect. It transpired that the correlation between market orientation and performance was rendered insignificant by the addition of CSR to the model, while the direct regression paths between market orientation, CSR and performance were significant. Despite interesting outcomes, the study suffers from limitations including a small sample size of 143 observations, the focus on a single, a narrowly defined industry (star-rated hotels in China) and a questionable choice of measurement scales (e.g. the whole of CSR involvement was assessed with only five Likert-scale items, which is much fewer than in most comparable projects), and financial performance was determined solely in relation to main competitors from a set of 3 self-reported qualitative metrics).

The third pertinent study [Galbreath, 2010] explored the question of whether companies employing different types of SO, using the already mentioned Miles and Snow typology, demonstrate different levels of CSR. According to Miles and Snow [1978, dominant strategic inclinations allow for distinguishing four general types of firms: prospectors, defenders, analyzers and reactors. In short, prospectors are the most pro-active firms, tending to rely on innovation and aggressive searching for new markets to attain first-mover advantage. Defenders opt to protect their current market share by relying on providing superior experience to customers and driving down costs through improved internal efficiency. Analyzers are a hybrid between prospectors and defenders, looking to maintain stable market positions but also open to exploiting new market opportunities, however, usually as followers (second movers) to prospectors. Reactors are those firms that suffer from strategies misaligned with their environment and resources; they tend to display inconsistent behaviour in response to strong stimuli from the market. Using a sample of 280 Australian companies from a wide range of industries, the author found significant effects of SO on CSR. ANOVA tests showed that prospectors and defenders displayed greater involvement in CSR than analyzers and reactors. As explained by the author, this effect in prospectors could be due to higher levels of skill in environmental scanning and information processing (to find out the true needs of various stakeholder groups), stronger responsiveness to changes in the environment and greater innovativeness (to effectively use CSR claims in leveraging the firm's market position). Also, prospectors were led more often by CEOs with a marketing background, who tend to better understand how to use CSR in market positioning. On the other hand, the main reason for defenders to attain high levels of CSR involvement was relatively longer tenures of their top managers, who, by staying longer on the job, had more time to develop tacit, idiosyncratic knowledge of the company and its surroundings. That knowledge enabled them to better evaluate risks involved in engaging in CSR, which - as suggested by other research - could 
have detrimental effects on performance. In addition, managers with longer tenures could develop closer and more personal ties with various stakeholder groups, prompting their stronger interest in supporting the well-being of those groups.

\section{Conceptual model and hypotheses}

Drawing on the outlined existing research and building on the assumptions noted in the introduction to the paper, the two main hypotheses are:

H.1 The relationship between SO and operational performance (OP) is mediated by CSR. H.2 SO is a moderating factor in the relationships between CSR and OP.

The first hypothesis tests the mediation effect of CSR that is the main focus of this study. The second hypothesis is a complement to the first one in that it provides a more complete picture of the relationships between CSR, SO and OP.

Following the classical Baron and Kenny's description of mediation [Barron and Kenny, 1986], it can be said that mediation occurs when the three conditions are met:

1. The independent variable must be significantly correlated with the mediating variable.

2. The mediating variable must be significantly correlated with the dependent variable.

3. The direct effect between the independent variable and dependent variable is considerably reduced, or drops to zero, after the introduction of the moderating variable into the model. From these guidelines the following graphical model is proposed for the relationships embedded in the main hypotheses.

Figure 1: Conceptual model of the research

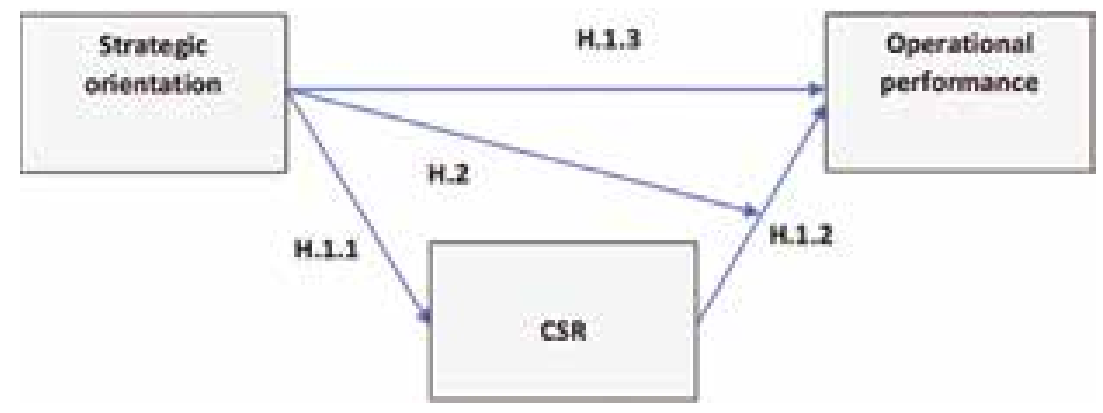

Source: Own elaboration.

The regression paths depicted by arrows in the model represent the three conditions for the moderation effect to occur, which correspond to a set of auxiliary hypotheses:

H.1.1 SO is correlated with CSR.

H.1.2 CSR is correlated with OP.

H.1.3 SO is correlated with OP only when CSR is unaccounted for. When CSR is factored into the regression model, SO is not significantly correlated with OP. 
The fourth path, connecting SO with the arrow between CSR and OP, represents a possible moderation effect of SO on the strength of the relationship from CSR to OP, which corresponds to the second main hypothesis (H.2).

\section{Research method}

\section{Sample and data collection}

To test the hypotheses, the study relied on a CATI survey of managers of small and medium-sized enterprises operating in Poland in the food industry (also including non-alcoholic beverage producers), which is among the three manufacturing industries with the greatest contributions to the Polish GDP (accounting for about 11\% of GDP in 2016) [Central Statistical Office, 2017]. At the same time, it comprises a large number of small and medium-sized companies with diversified levels of technological and managerial sophistication. A sample for the survey was selected at random from a complete database of food and beverage industry manufacturers in Poland by a research agency hired for the project; the research agency was also responsible for contacting and collecting answers from the managers. The total of 400 interviews was completed for a response rate of approximately $41 \%$ (i.e. the initial sample size was 976 , of which 576 contact attempts were unsuccessful mostly due to refusals). After initial screening, 31 cases were excluded because of missing answers and large inconsistencies in answers, strongly suggestive of measurement errors. The measurement errors possibly arose from lapses in attention of a small group of the respondents who misinterpreted some questions and response items. Overall, 369 records were used in further analysis.

\section{Measurement scales}

The companies' involvement in sustainable management was established with a multi-item Likert scale, where the respondents had to agree or disagree with a series of statements about various manifestations of sustainability it their firms. The possible answers could take 5 discrete values, from "strongly disagree" to "strongly agree". The content of particular items, addressed dimensions of sustainable management and literature sources for the scale items were shown in Table 1. Following the existing published sources listed in the table, the four dimensions of CSR were assumed to be reflective, with the direction of the causal relationships from the latent variables to their indicators (i.e. Liker scale items).

The index of operational performance was computed as a summation of 13 binary indicator variables - each of the variables representing a different favorable effect of sustainable management in the 3 years preceding the interview (2012-2014). The presence of each of the effects was marked as 1 , while the lack thereof as 0 . The choice of the sustainability effects was 
based on the existing literature, in particular the scales used by Torugsa et al. [2012] and Green et. al. [2014]. The complete list of indicator items comprising the index was given in Table 2 .

Table 1: Likert-scale items used for measuring CSR dimensions in the study

\begin{tabular}{|c|c|}
\hline Item content & Literature sources \\
\hline \multicolumn{2}{|l|}{ Latent variable: Employee Relations } \\
\hline $\begin{array}{l}\text { Employees have access to training developing skills not only useful in the current position but also } \\
\text { in their future career. }\end{array}$ & \multirow{5}{*}{$\begin{array}{l}\text { Buciuniene and } \\
\text { Kazlauskaite [2012], } \\
\text { Zaborek [2014], } \\
\text { Tang et al. [2012] }\end{array}$} \\
\hline $\begin{array}{l}\text { We have an equal chances policy whereby no one is discriminated against and everyone can be } \\
\text { promoted. }\end{array}$ & \\
\hline In important matters the management consults employees. & \\
\hline Our employees' wages are higher than in similar firms in our industry. & \\
\hline We strive to ensure that employees can find a balance between their professional and personal life. & \\
\hline \multicolumn{2}{|l|}{ Latent variable: Natural Environment } \\
\hline $\begin{array}{l}\text { In developing new products, we consider environmental impacts regarding their manufacturing, use } \\
\text { and recycling. }\end{array}$ & \multirow{5}{*}{$\begin{array}{l}\text { Elkington [1998], } \\
\text { Lagoarde-Segot [2011], } \\
\text { Saleh et al. [2011], } \\
\text { Torgusa et. al. [2012], } \\
\text { Zaborek [2014] }\end{array}$} \\
\hline We seek to generate lower air pollution. & \\
\hline Our technologies and manufacturing processes are environmentally friendly. & \\
\hline In manufacturing, we use almost exclusively ecological materials and components. & \\
\hline Our company offers to all interested parties full and accurate information about environmental impacts. & \\
\hline \multicolumn{2}{|l|}{ Latent variable: Market Policies } \\
\hline We always pay our financial obligations in a timely manner. & \multirow{3}{*}{$\begin{array}{l}\text { Maloni and Brown [2006], } \\
\text { Hsueh and Chang [2008], } \\
\text { Cruz and Matsypura } \\
\text { [2009] }\end{array}$} \\
\hline We handle complaints from our customers, suppliers and other business partners without delay. & \\
\hline We cooperate with other companies and organizations to promote sustainable business practices. & \\
\hline \multicolumn{2}{|l|}{ Latent variable: Local Impacts } \\
\hline We source from local suppliers. & \multirow{5}{*}{$\begin{array}{l}\text { Mishra and Suar [2010], } \\
\text { Saleh et al. [2011], } \\
\text { Zaborek [2014] }\end{array}$} \\
\hline $\begin{array}{l}\text { We encourage employees to participate in events organized by local communities, permitting them, for } \\
\text { example, to do it during working hours or to use material and immaterial resources of the company. }\end{array}$ & \\
\hline We periodically measure our involvement is social activities. & \\
\hline Our social and environmental initiatives are based on cooperation with local entities. & \\
\hline $\begin{array}{l}\text { Before starting a new project, we evaluate its possible impacts on the local environment and } \\
\text { communities. }\end{array}$ & \\
\hline
\end{tabular}

Source: Own elaboration.

Table 2: Components of the index of operational performance. All the listed effects concert the 3-year period preceding the interview (2012-2014)

\begin{tabular}{|l|}
\hline 1. Lower employee absences \\
\hline 2. Lower employee turnover \\
\hline 3. Lower work accidents \\
\hline 4. Fewer product returns \\
\hline 5. Smaller percentage of products failing to meet internal quality criteria \\
\hline 6. Higher percentage of returning customers \\
\hline 7. Fewer conflicts with supply chain members \\
\hline
\end{tabular}




\begin{tabular}{|l|}
\hline 8. Lower use of raw materials per unit of a product \\
\hline 9. Lower use of energy per unit of a product \\
\hline 10. Lower use of water in production \\
\hline 11. Reduced gas emissions \\
\hline 12. Increased share of recycled materials in the total use of materials \\
\hline 13. Reduced number of violations of environmental regulations \\
\hline
\end{tabular}

Source: Own elaboration.

The conceptualization of SO in this study was guided by the work of N. Venkatram [1989], and included the following facets:

- Aggressiveness is a company's stance to grow faster than its competitors and increase the market share by the appropriate allocation of resources and deploying ambitious action plans and programmes.

- Analysis, which refers to a problem-solving attitude, entailing search for the roots of a problem and developing possible solutions.

- Defensiveness is manifested by an emphasis on cost reductions, search for productivity gains and protection of proprietary technology to preserve one's own market position.

- Future orientation concerns a firm's relative focus on long term targets versus short term objectives.

- Proactiveness represents an attitude and capacity for actively seeking new opportunities, often above and beyond the current scope of the operation of a company.

- Risk propensity in terms of resource allocation and the choice of products and markets These six constructs were measured with Likert scale items adapted for the context of this research from batteries of statements developed by Venkatran [1989], and later amended by Morgan and Strong [1997]. The scales used to measure SO were given in Table 3.

Table 3: Likert scale items for strategic orientation

\begin{tabular}{|l|l|}
\hline \multicolumn{1}{|c|}{ Item content } & \multicolumn{1}{|c|}{$\begin{array}{c}\text { Dimension of } \\
\text { strategic orientation }\end{array}$} \\
\hline We often sacrifice profitability to gain market share. & Aggressiveness \\
\hline We often cut prices to increase market share. & \\
\hline We often set prices below competition. & Analysis \\
\hline We often seek desired market share position at the expense of cash flow and profitability. & \\
\hline We systematically gather and analyze market information. & \\
\hline Market analysis outcomes are readily available to all decision makers. & Defensiveness \\
\hline We continuously monitor our competitive position. & \\
\hline When confronted with a major decision we always analyze it thoroughly. & \\
\hline Market information drives the work of all departments in our company. & \\
\hline We regularly conduct significant modifications to manufacturing technology. & \\
\hline The main criterion in performance evaluation of the whole firm and its individual departments is cost analysis. & \\
\hline We routinely use formalized methods of production management. & \\
\hline We often modify our products following ideas from our employees. & \\
\hline
\end{tabular}




\begin{tabular}{|l|l|}
\hline Our action plans focus on long-term goals. & Future orientation \\
\hline Long-term goals are prioritized over short-term goals. & \\
\hline In planning we use long-term forecasts of crucial metrics. & \\
\hline $\begin{array}{l}\text { We continuously track important trends in the environment, such as demographical, cultural and } \\
\text { technological. }\end{array}$ & \multirow{2}{*}{ Proactiveness } \\
\hline We constantly seek for new opportunities going beyond our present operations. & \\
\hline $\begin{array}{l}\text { We are often among the first firms in the industry to introduce innovations, such as new products or } \\
\text { production processes. }\end{array}$ & Risk propensity \\
\hline We seek to implement the most innovative solutions in the industry. & \\
\hline Our planning system is flexible enough to enable making use of unexpected opportunities. & \\
\hline In taking decisions we place a great emphasis on reducing risk. & \\
\hline We mostly involve in projects where the expected benefits are certain. & \\
\hline We usually employ "tried and true" solutions in organizing production and sales. & \\
\hline
\end{tabular}

Source: Adapted from Venkatran [1989] and Morgan and Strong [1997].

In the research by Venkatran [1989] and Margan and Strong [1997] the dimensions of SO were assumed to be reflective constructs, recognized by highly correlated indicators under each dimension. In the present study, however, we were unable to detect sufficiently strong correlation patterns to build a robust measurement model with SO dimensions as reflective latent variables. Accordingly, it was assumed that each dimension was in fact a formative construct that was created by combining individual effects of its indicators. This assumption is opposite to that for reflective constructs, where indicator variables are just reflections of a directly non-measurable and more general variable. In other words, under a reflective specification, latent variables define indicators, while in a formative model it is indicators that define constructs [Borsboom, 2005]. Consequently, in reflective constructs indicators must be correlated if they are to measure the same latent variable, while such a condition does not apply to indicators defining formative constructs.

There has been longstanding dispute in academia about the true nature of popular constructs employed for studying firms, such as market orientation, entrepreneurial orientation, CSR, etc. As an example, Anderson et al. [2015] propose that entrepreneurial orientation (which is often considered a form of strategic orientation) is best operationalized as a formative second-order construct, as opposed to a more popular reflective model, and they demonstrate that the formative approach yields a model with superior statistical and substantive qualities versus its reflective equivalent, even though the latter was still admissible. Regarding CSR, an interesting discussion of building a measurement scale with formative characteristics can be found in Isa and Reast [2014]. In the context of the current study, the issue of operationalizing market orientation is particularly relevant, since this concept is considered a special kind of strategic orientation, and as such should follow similar measurement principles. A comparison of the two measurement models - formative and reflective - for market orientation can be found in Coltman et al. [2008]. Both competing models use the same set of indicators but with the opposite directions of links to underlying constructs. Extensive tests performed by the authors suggest that the formative model works better in terms discriminant and nomological 
validity, and it also offers greater predictive power. Overall, the findings of the study seem to give support to the specification of SO (as a more general concept than market orientation) with the formative approach.

To conclude, building on the cited arguments the current research treats the SO dimensions as formative latent constructs.

\section{Statistical methods}

The first step in statistical analysis was to establish the scores of the latent variables. For this purpose, the CSR dimensions, being reflective constructs, were estimated thorough confirmatory factor analysis with AMOS 24. The formative aspects of SO were computed as arithmetic averages of their indicators, and the composite metric of OP was a simple summary of the reported binary effects. The scores of all latent characteristics were saved as new variables and used in estimating multiple regression models in SPSS 24.

\section{Research findings}

Confirmatory factor analysis yielded a measurement model for CSR with four reflective dimensions.

In order to evaluate the model fit with the empirical data in the sample, a standard set of metrics was used. The values of these metrics together with conventional cut-off points were given in Table 4.

Table 4: Overall fit measures for the SEM model

\begin{tabular}{|l|l|l|}
\hline \multicolumn{1}{|c|}{ Metric } & \multicolumn{1}{c|}{ Value } & \multicolumn{1}{c|}{ Threshold for a well-fitting model } \\
\hline Chi-square/df (relative chi-square) & 2.880 & $<3$ for good fit \\
\hline p-value for the model & $<0.001$ & $>0.05$ \\
\hline GFI (goodness of fit index) & 0.924 & $\geq 0.9$ \\
\hline CFI (comparative fit index) & 0.943 & $\geq 0.9$ \\
\hline AGFI (adjusted goodness of fit index) & 0.857 & $\geq 0.8$ \\
\hline PCFI (parsimony comparative fit index) & 0.803 & $\geq 0.8$ \\
\hline RMSEA (root mean square of approximation) & $\begin{array}{l}0.071 ; \\
\text { HI90=0.079 }\end{array}$ & $\begin{array}{l}\leq 0.05 \text { for good model fit; } \leq 0.08 \text { for adequate fit; in addition, the } \\
\text { for a well-fitting model }\end{array}$ \\
\hline
\end{tabular}

Source: Own elaboration. Cutoff points based on Garson [2012].

The reported indices indicate a close match between the model and the data. The only exception is the chi-square test, which is significant and rejects the null hypothesis of the lack of differences between the observed covariance matrix and the one implied by the model. However, the chi-square statistic tends to be excessively inflated for large samples, such as 
in the current analysis, which leads to increased sensitivity of the test. As such, this measure is considered unreliable and could be disregarded if other metrics point to a well-fitting solution [Garson, 2012, pp. 76-77; Bowen and Guo, 2012, p. 142].

The next table provides insights into CSR dimensions in terms of reliability (Cronbach's Alpha), convergent validity (AVE, or average variance extracted) and discriminant validity (MSV, or maximum shared variance).

Table 5: Reliability and validity measures of CSR involvement dimensions

\begin{tabular}{|l|c|c|c|}
\hline \multicolumn{1}{|c|}{ Construct } & Cronbach's Alpha & AVE & MSV \\
\hline Local impacts & 0.865 & 0.572 & 0.490 \\
\hline Market policies & 0.853 & 0.710 & 0.130 \\
\hline Natural environment & 0.887 & 0.610 & 0.490 \\
\hline Employee relations & 0.889 & 0.666 & 0.476 \\
\hline
\end{tabular}

Source: Own elaboration.

The metrics in Table 5 indicate a solution without any apparent issues compromising its interpretability. It seems that the manifest variables used to represent the latent constructs have high levels of internal consistency - Cronbach's alphas are all greater than 0.07 , as suggested in Malhotra [Malhotra, 2010, p. 287]. AVE values, which show how well hidden variables are represented by their corresponding indicators, should be at least 0.5 [Hair et al., 2007, p. 605], which is true for all the constructs. Also, the model does not appear to suffer from issues with discriminant validity, as all latent variables had the average extracted variance (AVE) greater than the maximum shared variance with other constructs (MSV); this implies that it is unlikely that any indicator measures better some other construct than the one it was formally ascribed to.

The descriptive statistics of the six composite variables representing the six dimensions of SO were displayed in Table 6.

Table 6: Descriptive statistics for the six dimensions of strategic orientation

\begin{tabular}{|c|c|c|c|c|c|c|c|c|}
\hline & \multirow{2}{*}{ Minimum } & \multirow{2}{*}{ Maximum } & \multirow{2}{*}{ Mean } & \multirow{2}{*}{$\begin{array}{c}\text { Std. } \\
\text { Deviation }\end{array}$} & \multicolumn{2}{|c|}{ Skewness } & \multicolumn{2}{|c|}{ Kurtosis } \\
\hline & & & & & Statistic & Std. Error & Statistic & Std. Error \\
\hline Aggressiveness & 1 & 5 & 3.8245 & .6479 & -1.138 & .127 & 1.958 & .253 \\
\hline Analysis & 1 & 5 & 4.0661 & .5379 & -1.424 & .127 & 2.815 & .253 \\
\hline Future orientation & 1 & 5 & 3.8155 & .6172 & -.670 & .127 & 1.165 & .253 \\
\hline Defensiveness & 1 & 5 & 3.7191 & .7164 & -.704 & .127 & .577 & .253 \\
\hline Proactiveness & 1 & 5 & 3.8462 & .5679 & -.942 & .127 & 1.922 & .253 \\
\hline Risk propensity & 1 & 5 & 3.9810 & .6269 & -.622 & .127 & .889 & .253 \\
\hline
\end{tabular}

Source: Own elaboration. 
It transpired that the average values of all the attributes of SO were beyond the neutral point of 3. The firms demonstrated the greatest levels of capacity for analysis (4.07), while the relatively weakest was the trait of defensiveness (3.2).

Figure 2: Frequency distributions of SO dimensions
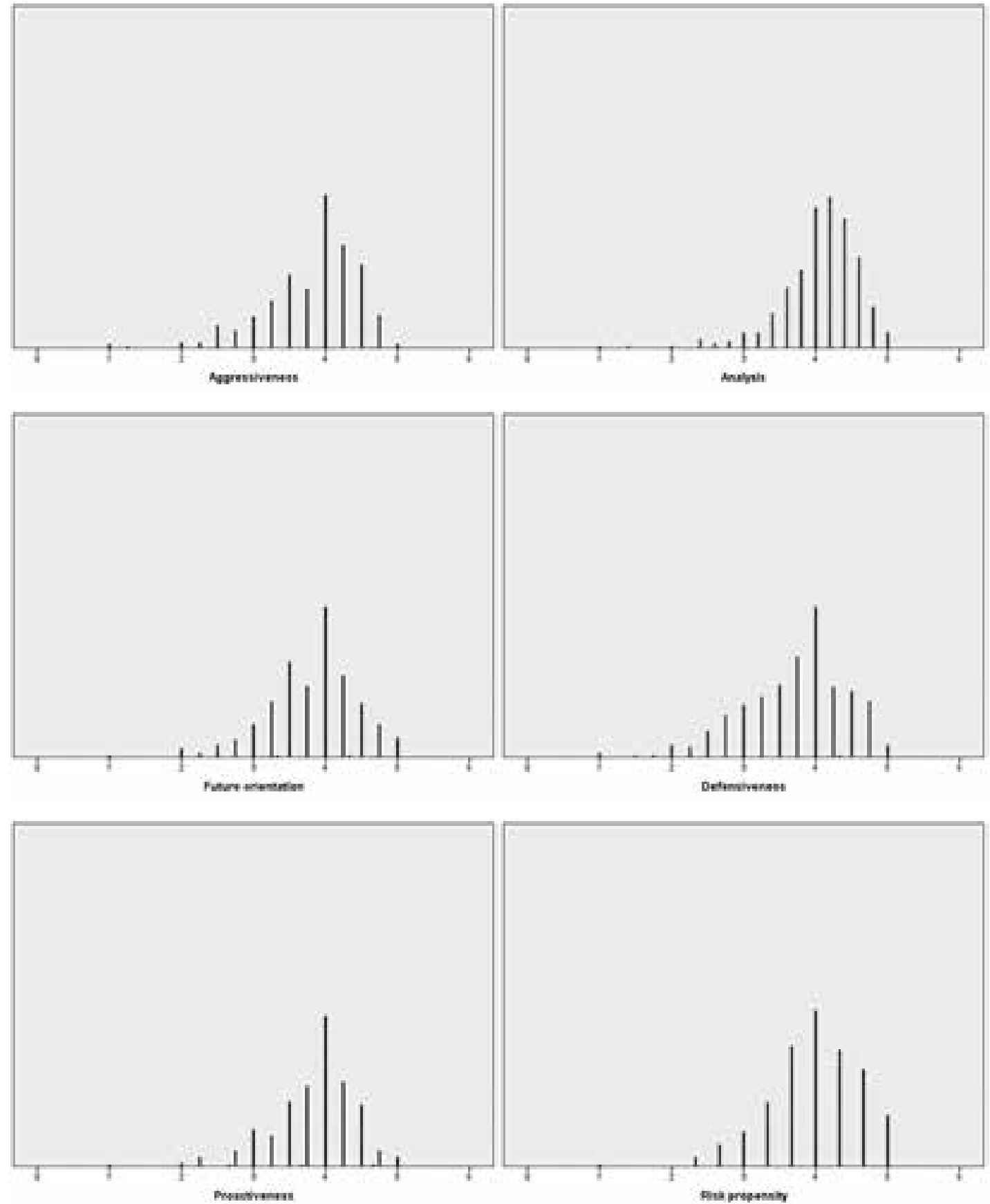

Source: Own elaboration. 
Even though the presented dot plots depict distributions with negative asymmetry, for no variable the strength of skewness is extreme, which could be problematic in further analysis (the lack of strong asymmetry is also confirmed by the descriptive statistics in the previous table, which do not exceed 1.5 in terms of absolute value that is often considered a threshold for extreme asymmetry).

Table 7: Correlations between pairs of SO dimensions

\begin{tabular}{|c|c|c|c|c|c|c|c|}
\hline & & Aggressiveness & Analysis & $\begin{array}{c}\text { Future } \\
\text { orientation }\end{array}$ & Defensiveness & Proactiveness & $\begin{array}{c}\text { Risk } \\
\text { propensity }\end{array}$ \\
\hline \multirow[t]{2}{*}{ Aggressiveness } & Pearson Correlation & 1 & $.279 * \star$ & $.304^{\star *}$ & $.238^{\star \star}$ & $.240^{\star *}$ & $.206^{\star \star}$ \\
\hline & Sig. (2-tailed) & & .000 & .000 & .000 & .000 & .000 \\
\hline \multirow[t]{2}{*}{ Analysis } & Pearson Correlation & $.279 * *$ & 1 & $.335^{\star \star}$ & $.256^{\star \star}$ & $.335^{\star \star}$ & $.210^{\star \star}$ \\
\hline & Sig. (2-tailed) & .000 & & .000 & .000 & .000 & .000 \\
\hline \multirow[t]{2}{*}{ Future orientation } & Pearson Correlation & $.304^{\star \star}$ & $.335^{\star \star}$ & 1 & $.277^{\star \star}$ & $.385^{\star \star}$ & $.347^{\star \star}$ \\
\hline & Sig. (2-tailed) & .000 & .000 & & .000 & .000 & .000 \\
\hline \multirow[t]{2}{*}{ Defensiveness } & Pearson Correlation & $.238^{\star *}$ & $.256^{\star *}$ & $.277^{\star \star}$ & 1 & $.229 * \star$ & $.238^{* *}$ \\
\hline & Sig. (2-tailed) & .000 & .000 & .000 & & .000 & .000 \\
\hline \multirow[t]{2}{*}{ Proactiveness } & Pearson Correlation & $.240^{\star \star *}$ & $.335^{\star \star}$ & $.385^{\star \star}$ & $.229 \star \star$ & 1 & $.273^{\star \star}$ \\
\hline & Sig. (2-tailed) & .000 & .000 & .000 & .000 & & .000 \\
\hline \multirow[t]{2}{*}{ Risk propensity } & Pearson Correlation & $.206^{\star \star}$ & $.210^{\star \star}$ & $.347^{\star \star}$ & $.238^{\star \star}$ & $.273^{\star *}$ & 1 \\
\hline & Sig. (2-tailed) & .000 & .000 & .000 & .000 & .000 & \\
\hline
\end{tabular}

${ }^{* *}$. Correlation is significant at the 0.01 level (2-tailed).

Source: Own elaboration.

The dimensions are only mildly correlated, which suggests that despite a certain amount of shared variance it is unlikely that they could be represented by the same second-order reflective construct, adding further support to the formative nature of the relationships underlying the concept of SO. Indeed, an exploratory factor analysis with the maximum likelihood method and the Keiser criterion performed on the six dimensions of SO extracts only one factor with $28 \%$ of shared variance, which is too small for a viable reflective solution. Weak correlations also imply that discriminant validity is not a problem as each dimension has its own distinct meaning.

To establish if variance in the indicators of CSR and SO were caused by substantive reasons rather than the use of the same types of scales on measures obtained from a single data source, Harman's single factor test for common method bias was performed [Fuller et al., 2015]. Accordingly, once all metrics for CSR and SO were loaded on a single factor, the amount of extracted variance was $20.8 \%$, which is lower than the threshold of $50 \%$, indicating that common method bias was of no concern.

The next step in the statistical analysis involved testing the research hypotheses with a series of multiple regression models. The first hypothesis (H.1.1), about the positive correlation between SO and CSR, was explored with four regression equations set out in the tables below. Significant predictors were marked in bold. 
Table 8: Regression model of the relationship between SO dimensions and the CSR dimension of employee relations ( $R$-squared for the model $=0.147$ )

\begin{tabular}{|l|c|c|c|c|c|}
\hline \multirow{2}{*}{ Model components } & \multicolumn{2}{|c|}{ Unstandardized Coefficients } & \multirow{2}{*}{$\begin{array}{c}\text { Standardized } \\
\text { Coefficients }\end{array}$} & t & Sig. \\
\cline { 2 - 5 } & $\mathrm{B}$ & Std. Error & Beta & & .000 \\
\hline (Constant) & -3.204 & .478 & & -6.703 & .001 \\
\hline Aggressiveness & .271 & .078 & .188 & 3.487 & .136 \\
\hline Analysis & .144 & .096 & .082 & 1.494 & .206 \\
\hline Future orientation & -.112 & .089 & -.074 & -1.266 & .043 \\
\hline Defensiveness & .145 & .071 & .109 & 2.028 & .000 \\
\hline Proactiveness & .349 & .092 & .212 & 3.782 & .607 \\
\hline
\end{tabular}

Dependent Variable: CSR: Employee relations.

Source: Own elaboration.

Table 9: Regression model of the relationship between SO dimensions and the CSR dimension of natural environment ( $R$-squared for the model $=0.123$ )

\begin{tabular}{|l|c|c|c|c|c|}
\hline \multirow{2}{*}{ Model components } & \multicolumn{2}{|c|}{ Unstandardized Coefficients } & \multirow{2}{*}{$\begin{array}{c}\text { Standardized } \\
\text { Coefficients }\end{array}$} & t & Sig. \\
\cline { 2 - 5 } & $\mathrm{B}$ & Std. Error & Beta & & .000 \\
\hline (Constant) & -3.115 & .486 & & -6.415 & .048 \\
\hline Aggressiveness & .157 & .079 & .108 & 1.987 & .553 \\
\hline Analysis & .058 & .098 & .033 & .538 & .591 \\
\hline Future orientation & .048 & .090 & .032 & 2.194 & .029 \\
\hline Defensiveness & .159 & .073 & .119 & $\mathbf{3 . 1 7 8}$ & .002 \\
\hline Proactiveness & .298 & .094 & .180 & 1.184 & .237 \\
\hline Risk propensity & .098 & .082 & .065 & & .25 \\
\hline
\end{tabular}

Dependent Variable: CSR: Environment.

Source: Own elaboration.

Table 10: Regression model of the relationship between SO dimensions and the CSR dimension of market policies ( $R$-squared for the model $=0.026$ )

\begin{tabular}{|c|c|c|c|c|c|}
\hline \multirow{2}{*}{ Model components } & \multicolumn{2}{|c|}{ Unstandardized Coefficients } & \multirow{2}{*}{$\begin{array}{c}\begin{array}{c}\text { Standardized } \\
\text { Coefficients }\end{array} \\
\text { Beta }\end{array}$} & \multirow{2}{*}{$t$} & \multirow{2}{*}{ Sig. } \\
\hline & B & Std. Error & & & \\
\hline (Constant) & -.272 & .502 & & -.542 & .588 \\
\hline Aggressiveness & -.026 & .076 & -.020 & -.337 & .736 \\
\hline Analysis & -.125 & .093 & -.078 & -1.345 & .180 \\
\hline Future orientation & .069 & .083 & .051 & .822 & .411 \\
\hline Defensiveness & -.041 & .068 & -.035 & -.611 & .542 \\
\hline Proactiveness & .208 & .089 & .139 & 2.347 & .020 \\
\hline Risk propensity & .033 & .078 & .025 & .425 & .671 \\
\hline
\end{tabular}

Dependent Variable: CSR: Market policies.

Source: Own elaboration. 
Table 11: Regression model of the relationship between SO dimensions and the CSR dimension of local impacts ( $R$-squared for the model $=0.126$ )

\begin{tabular}{|c|c|c|c|c|c|}
\hline \multirow{2}{*}{ Model components } & \multicolumn{2}{|c|}{ Unstandardized Coefficients } & \multirow{2}{*}{$\begin{array}{c}\begin{array}{c}\text { Standardized } \\
\text { Coefficienasts }\end{array} \\
\text { Beta }\end{array}$} & \multirow{2}{*}{$t$} & \multirow{2}{*}{ Sig. } \\
\hline & B & Std. Error & & & \\
\hline (Constant) & -2.847 & .479 & & -5.940 & .000 \\
\hline Aggressiveness & .283 & .078 & .198 & 3.613 & .000 \\
\hline Analysis & .163 & .097 & .094 & 1.687 & .093 \\
\hline Future orientation & .009 & .089 & .006 & .105 & .916 \\
\hline Defensiveness & .008 & .074 & .006 & .108 & .914 \\
\hline Proactiveness & .319 & .095 & .193 & 3.372 & .001 \\
\hline Risk propensity & -.038 & .082 & -.026 & -.464 & .643 \\
\hline
\end{tabular}

Dependent Variable: CSR: Local impacts.

Source: Own elaboration.

The reported regression analysis points to those aspects of SO that covary with elements of CSR in a systematic and meaningful way. For employee relations the significant predictors - all with positive impacts - are: aggressiveness, defensiveness and reactiveness. The natural environment has positive and significant linkages with the same set of three predictors, while local impacts show meaningful associations with aggressiveness and proactiveness. At $2.6 \%$ of variance accounted for by the model, market policies is the worst explained CSR construct in terms of SO, but even here the equation contains one significant predictor of proactiveness.

Overall, it does seem that SO has a significant impact on CSR implementation in business. The effect sizes vary from $14.7 \%$ of the explained variance in the case of employee relations to $2.6 \%$ for market policies. Having in mind that CSR is a complex concept that is known to be affected by multiple actors, events and other influences from the inside and outside of the company, the effect sizes obtained should be considered not only statistically significant but also practically meaningful (the unexplained variance represents all other systematic and random factors not controlled by the models). Interestingly, half of the SO dimensions seem to have no relevance to CSR at all: analysis, future orientation and risk propensity were not found to have significant associations with any of the CSR subconstructs.

The performed regression analyses give at least partial support to Hypothesis 1.1, as it is clear that some aspects of SO are conducive to more socially responsible behaviour of the companies.

The two remaining supportive hypotheses (H.1.2 and H.1.3) were verified by two further regression models. The first one links the index of operational performance with SO dimensions to see if there is any significant effect without mediation by CSR. Another equation adds CSR dimensions to the OP predictors to find out if the previously significant SO elements have lost their effects in favour of CSR dimensions. As before, significant variables were emphasized in bold. 
Table 12: Regression models predicting operational performance index from SO dimensions alone, and from SO dimensions combined with CSR subconstructs ( $R$-squared for the first model $=0.099 ;$-squared for the second model $=0.849$ )

\begin{tabular}{|c|c|c|c|c|c|c|}
\hline \multirow{2}{*}{\multicolumn{2}{|c|}{ Model }} & \multicolumn{2}{|c|}{ Unstandardized Coefficients } & \multirow{3}{*}{$\begin{array}{c}\text { Standardized } \\
\text { Coefficients } \\
\text { Beta }\end{array}$} & \multirow[t]{2}{*}{$\mathrm{t}$} & \multirow[t]{2}{*}{ Sig. } \\
\hline & & $B$ & Std. Error & & & \\
\hline \multirow[t]{7}{*}{1} & (Constant) & 3.310 & 1.313 & & 2.520 & .012 \\
\hline & Aggressiveness & .483 & .215 & .125 & 2.248 & .025 \\
\hline & Analysis & .179 & .265 & .038 & .676 & .500 \\
\hline & Future orientation & -.124 & .245 & -.030 & -.506 & .613 \\
\hline & Defensiveness & .102 & .202 & .028 & .504 & .615 \\
\hline & Proactiveness & 1.075 & .259 & .241 & 4.147 & .000 \\
\hline & Risk propensity & .041 & .224 & .010 & .182 & .856 \\
\hline \multirow[t]{11}{*}{2} & (Constant) & 11.450 & .582 & & 19.660 & .000 \\
\hline & Aggressiveness & -.109 & .091 & -.028 & -1.201 & .230 \\
\hline & Analysis & -.114 & .110 & -.024 & -1.036 & .301 \\
\hline & Future orientation & -.088 & .101 & -.022 & -.864 & .388 \\
\hline & Defensiveness & -.050 & .084 & -.014 & -.595 & .552 \\
\hline & Proactiveness & .057 & .110 & .013 & .519 & .604 \\
\hline & Risk propensity & -.073 & .093 & -.018 & -.786 & .433 \\
\hline & CSR: Employee relations & .455 & .089 & .171 & 5.106 & .000 \\
\hline & CSR: Environment & 1.060 & .094 & .389 & 11.279 & .000 \\
\hline & CSR: Market policies & .531 & .058 & .206 & 9.171 & .000 \\
\hline & CSR: Local impacts & 1.025 & .094 & .380 & 10.871 & .000 \\
\hline
\end{tabular}

Dependent variable: Operational performance index.

Source: Own elaboration.

The comparison of the two regression equations leads to several pertinent findings. First, the addition of CSR variables to the second model substantially improves the predictive power with the second model accounting for $85 \%$ of variance in operational performance compared to $9.9 \%$ for the first equation. This effect could be ascribed to the explanatory capacity of CSR. Despite being much weaker, the first model is still significant with two aspects of SO (aggressiveness and proactiveness) positively correlating with operational performance. However, once CSR elements are included, not a single dimension of SO continues to be significant. That loss of significance can be interpreted as a confirmation of the mediating role of CSR, whose dimensions were all strongly associated with the performance metric. Thus, Hypotheses 1.2 and 1.3 were supported by the empirical evidence.

Hypothesis 2 about the moderation effect of SO on the correlation between CSR and $\mathrm{OP}$ will be verified using a regression model with only one variable representing the whole involvement in CSR. Here, CSR is conceptualized as a second order formative construct, and - arithmetically - is the mean of scores for all four dimensions of CSR. This lower level of detail (one CSR variable versus four CSR dimensions) would permit to test the moderation 
effect in a more concise way by adding only 6 interaction terms, instead of 24 that would be required if the four dimensions of CSR were used. As such, by using much fewer parameters, the former model is more parsimonious making it also more reliable and powerful.

To compare with the final model for the first hypothesis (Table 12), the next table contains the parameters of the multiple regression accounting for the dimensions of SO and overall CSR involvement, but without interactions.

Table 13: Model regressing the operational performance index on dimensions of SO and overall CSR involvement ( $R$-squared for the model $=0.802$ )

\begin{tabular}{|l|c|c|c|c|}
\hline \multirow{2}{*}{ Model components } & \multicolumn{2}{|c|}{ Unstandardized Coefficients } & \multirow{2}{*}{ Sig. } \\
\cline { 2 - 3 } & $\mathrm{B}$ & Std. Error & & $\mathbf{. 0 0 0}$ \\
\hline (Constant) & $\mathbf{1 1 . 5 1 9}$ & $\mathbf{. 6 5 9}$ & $\mathbf{1 7 . 4 7 9}$ & .253 \\
\hline Aggressiveness & -.117 & .102 & -1.145 & .263 \\
\hline Analysis & -.140 & .125 & -1.121 & .891 \\
\hline Future orientation & .016 & .115 & .137 & .569 \\
\hline Defensiveness & -.052 & .092 & -.569 & .880 \\
\hline Proactiveness & .018 & .123 & .150 & .207 \\
\hline Risk propensity & -.133 & .105 & -1.265 & .000 \\
\hline CSR involvement & $\mathbf{3 . 1 5 4}$ & .089 & $\mathbf{3 5 . 6 0 5}$ & \\
\hline
\end{tabular}

Dependent Variable: Operational performance index.

Source: Own elaboration.

The model making use of the overall CSR involvement variable leads to the same conclusions about the mediating role of CSR. This suggests that the model can also be a reliable basis on which to make tests for SO moderation.

The final regression analysis includes all the variables from the previous model, with the addition of 6 interaction terms.

Table 14: Model regressing the operational performance index on dimensions of SO and overall CSR involvement with SO-CSR interaction ( $R$-squared for the model $=0.812$ )

\begin{tabular}{|l|c|c|c|c|}
\hline \multirow{2}{*}{\multicolumn{1}{|c|}{ Model components }} & \multicolumn{2}{|c|}{ Unstandardized Coefficients } & \multirow{2}{*}{ Sig. } \\
\cline { 2 - 4 } & $\mathrm{B}$ & Std. Error & & .000 \\
\hline (Constant) & 10.838 & .706 & 15.344 & .212 \\
\hline Aggressiveness & -.127 & .101 & -1.250 & .693 \\
\hline Analysis & -.051 & .129 & -.396 & .920 \\
\hline Future orientation & .011 & .114 & .101 & .558 \\
\hline Defensiveness & -.053 & .091 & -.586 & .526 \\
\hline Proactiveness & .077 & .122 & .635 & .300 \\
\hline Risk propensity & -.110 & .106 & -1.037 & .000 \\
\hline CSR involvement & 2.223 & .341 & 6.529 & .006 \\
\hline Aggresiveness * CSR involvement & .395 & .143 & 2.751 & \\
\hline
\end{tabular}




\begin{tabular}{|l|c|c|c|c|}
\hline \multirow{2}{*}{ Model components } & \multicolumn{2}{|c|}{ Unstandardized Coefficients } & \multirow{2}{*}{$\mathrm{t}$} & \multirow{2}{*}{ Sig. } \\
\cline { 2 - 3 } & $\mathrm{B}$ & Std. Error & & .834 \\
\hline Analysis * CSR involvement & .041 & .195 & .210 & .536 \\
\hline Future_orientation * CSR involvement & -.094 & .152 & -.620 & .577 \\
\hline Defensiveness * CSR involvement & .079 & .141 & .559 & .749 \\
\hline Proactiveness * CSR involvement & .050 & .156 & .320 & .226 \\
\hline Risk_propenisity * CSR involvement & -.179 & .148 & -1.212 & \\
\hline
\end{tabular}

Dependent Variable: Operational performance index. Source: Own elaboration.

The moderation effect was found significant for only one aspect of SO, aggressiveness. This implies that firms that take a more aggressive strategic stance also tend to have a stronger positive link between CSR and OP. Because the other elements of SO are not significant mediators, Hypothesis 2 finds only partial support in the data.

\section{Conclusions, limitations and directions for further research}

The proposition that involvement in CSR is not only a charitable whim of owners and managers but it can also lead to substantial benefits to the company has been long explored and substantiated by empirical evidence from many countries and industries. The same was found to be true in the current research: CSR involvement, both in the form of individual indicators as well as the general metric - showed strong positive associations with operational performance.

An interesting question that has been only rarely looked at in past research is the relationship between CSR and other non-tangible attributes of the company, such as organizational culture, market orientation and strategic orientation. In the literature these attributes are seen as capabilities and are not assumed to be driving performance directly but rather through the mediation of strategy, which is devised and implemented on the foundation of these capabilities [Barney 1991, Grant 1991]. Considering that CSR activities are reflections of a strategy, they could serve as a "go-between" in the causal path from capabilities to performance. The focus of this study - strategic orientation - was hypothesized to be linked to CSR as both an antecedent and moderator of the association from CSR to OP. Previous studies provide some confirmation of the mediation effect, but idiosyncratic research contexts in some of said studies (e.g. an exotic country or an atypical industry) could call into question the reliability and validity of such findings. In the present research, with the use of a large, random sample of the Polish food manufacturing industry, both mediation and moderation were corroborated. Following Baron and Kenny's protocol for identifying mediation, CSR displayed strong mediation properties, turning insignificant regression coefficients for the dimensions of SO, after being plugged into the model. Interestingly, even though any direct influence of SO on 
OP was removed by the addition of CSR, there was one effect that was not confounded - the moderation of the correlation between CSR and OP by aggressiveness. This outcome suggests that firms with a stronger aggressive streak in their strategic stance tend to implement CSR more effectively to gain more benefits from the CSR involvement of the same intensity. This effect is in addition to a direct positive bond between the three $\mathrm{SO}$ aspects of aggressiveness, proactiveness and defensiveness and the CSR dimensions, which implies that firms where these strategic traits are stronger also more frequently act in agreement with CSR principles. These findings correspond with the research by Qu [2009], who established CSR mediation between market orientation and financial performance. Considering that market orientation and strategic orientation are both forms of organizational culture and their dimensions tend to be correlated, the pattern discovered by $\mathrm{Qu}$ is like the one in the present study, which gives added support to the notion that CSR is placed in the middle of a causal chain between aspects of organizational culture and performance. The fact that the cited research sourced data from the hotel industry in China suggests that this CSR role is valid for both the manufacturing and services sector, and possibly not limited to only one country.

The strongest association of aggressiveness and proactiveness with CSR is in agreement with the work of Galibreath [2010], who found that firms described as prospectors showed stronger involvement in CSR than three other types of companies (analyzers, defenders and reactors). Prospectors have comparatively greatest levels of aggressiveness and proactiveness, which leads to the same conclusion as in the present study. Moreover, the corporate capacity labeled as strategic proactiveness and measured using similar scale items to this study's proactiveness was found to be a significant antecedent of CSR by Torgusa et al. [2011,2012] in a model which also tested the mediating function of CSR with financial performance as the final endogenous (dependent) variable.

From a practical standpoint, the outcomes show that part of the positive effects of CSR may come from more general strategic stances and attitudes. Also, it seems that certain aspects of strategic orientation might be more effective when implemented in an organizational environment with strong CSR values. This is particularly relevant for more dynamic strategies with high levels of aggressiveness and proactiveness - it seems that a heightened social sensitivity can make those modes of operation work better.

In light of these findings it can be concluded that SO goes hand in hand with CSR to create the synergy that benefits both companies through enhanced performance and various stakeholder groups via ethical policies, programmes and actions. The need for developing CSR in harmony with other internal capacities of the company with a particular focus on synergy between CSR and organizational culture was also given as a recommendation in an earlier paper by Tang et al. [2012].

The study is not without its constraints. First, the cross-sectional survey method has limited capacity to detect causal relationships - the effects found here are truly only a statistical association and a casual interpretation can be given only based on a substantive theory. It is a particularly pertinent issue since, as shown by earlier research [Nelling \&Webb, 2009], 
the effect of CSR on performance can be stronger in a cross-sectional approach than in longitudinal analysis for the same set of firms. Also, collecting data about companies by asking questions of managers can make it difficult to separate facts from opinions and conjectures. To limit the possibility of bias in the data, the survey was carefully designed with well-established multi-item scales, but this inherent constraint of the survey method cannot be entirely remedied. It should be noted that the study concerns only a single industry of food manufacturers in Poland, and the patterns relevant for this population may not be directly transferable to firms in other industries in different countries.

Overall, considering the above limitations, further research on this topic could benefit from using panel data in a longitudinal design with more reliance on factual data instead of manager opinions. Also, a cross-validation in a different industry and country setting could be instrumental in determining how universal the patterns detected in this study are.

\section{References}

1. Aluchna, M., 2017. From Ideas to Impacts: CSR in the Eyes of Top Managers in Poland. In S. Idowu, S. Vertigans (Eds), Stages of Corporate Social Responsibility: From Ideas to Impacts, Switzerland: Springer International Publishing, 47-66.

2. Anderson B.S., Kreiser P.M., Kuratko D.F., Hornsby J.S., Eshima Y., 2015. Reconceptualizing entrepreneurial orientation. Strategic Management Journal, 36, 1579-1596.

3. Balodi C.B., 2014. Strategic orientations and organizational forms: an integrative framework. European Business Review, 26(2), 188-203

4. Barney, J.B., 1991. Firm resources and sustained competitive advantage. Journal of Management, 17(1), 99-120.

5. Barron R.M., Kenny D.A., 1986. The moderator-mediator variable distinction in social psychological research: Conceptual, strategic and statistical considerations. Journal of Personality and Social Psychology, 51, 1173-1182.

6. Bello, Z., 2005. Socially responsible investing and portfolio diversification. Journal of Financial Research, 28, 4-57.

7. Borsboom D., 2005. Measuring the Mind: Conceptual Issues in Contemporary Psychometrics. Cambridge, UK: Cambridge University Press.

8. Bowen, N.; Guo, S., 2012. Structural Equation Modeling: Pocket Guides to Social Research Methods. New York, NY, USA: Oxford University Press.

9. Buciuniene I., Kazlauskaite R., 2012. The linkage between HRM, CSR and performance outcomes, Baltic Journal of Management, 7(1). 5-24.

10. Byrne, B., 2010. Structural Equation Modeling with AMOS: Basic Concepts, Applications and Programming, 2nd ed. New York, NY, USA: Routledge.

11. Carroll, A.B., 1999. Corporate social responsibility, evolution of a definitional construct. Business and Society, 38, 268-295.

12. Central Statistical Office, 2017. Statistical Yearbook of Industry - Poland: Branch Yearbooks. 
13. Coltman, T., Devinney, T.M., Midgley, D.F., Veniak S., 2008. Formative versus reflective measurement models: Two applications of formative measurement. Journal of Business Research, 61, pp. 1250-1262.

14. Cruz M., Matsypura D., 2009. Supply chain networks with corporate social responsibility through integrated environmental decision-making. International Journal of Production Research, 47(3). 621-648.

15. Elkington, J., 1998. Cannibals with forks: The triple bottom line of the 21st Century Business. Environmental Quality Management, 8(1), 37-51.

16. Fuller, C.M., Simmering, M.J., Atinc, G., Atinc, Y., \& Babin, B.J., 2016. Common methods variance detection in business research. Journal of Business Research, 69(8), 3192-3198.

17. Galbreath J., 2010. The impact of strategic orientation on corporate social responsibility. International Journal of Organizational Analysis, 18(1), 23-40.

18. Garson, D., 2012. Structural Equation Modeling. Statistical Association Publishing Blue Book Series. Asheboro: Statistical Association Publishing.

19. Grant, R.M., 1991. The resource-based theory of competitive advantage: Implications for strategy formulation. California Management Review, 33(3), 114-135.

20. Hair, J., Black,W., Babin, B., Anderson, R., 2007. Multivariate Data Analysis, 7th ed. Upper Saddle River, NJ, USA: Prentice-Hall.

21. Hakala H., 2011. Strategic orientations in management literature: three approaches to understanding the interaction between market, technology, entrepreneurial and learning orientations. International Journal of Marketing Reviews, 13(2), 199-217.

22. Hsueh, C.F.; Chang, M.S., 2008. Social Responsibility for Supply Chain Integration. European Journal of Operational Research, 190(1), 116-129.

23. Isa, M.S., Reast, J., 2014. Operationalising Corporate Social Responsibility (CSR) and Development Debate. Asian Academy Management Journal, 16(1), 169-197.

24. Jayachandran S., Kalaignanam,K., Eilert A.M., 2013. Product and environmental social performance: varying effect on firm performance. Strategic Management Journal, 35, 1255-64.

25. Johnson J., Martin K., Saini A., 2012. The role of a firm's strategic orientation dimensions in determining market orientation. Industrial Marketing Management, 41, 715-724.

26. Kang C., Germann F., Grewal R., 2016. Washing away sins? Corporate social responsibility, corporate social irresponsibility, and firm performance. Journal of Marketing, 80(3), 59-79.

27. Lagoarde-Segot T., 2011. Corporate Social Responsibility as a Bolster for Economic Performance: Evidence from Emerging Markets. Global Business and Organizational Excellence, 6, 38-53.

28. Lu, W., Chau, K., Wang, H., Pan, W., 2014. A decade's debate on the nexus between corporate social and financial performance: a critical review of empirical studies 2002-2011. Journal of Cleaner Production, 79, 195-206.

29. Luo, X., Bhattacharya, C.B., 2006. Corporate social responsibility, customer satisfaction, and market value. Journal of Marketing, 70, 1-18.

30. Maignan I., Ferrell O.C., Hull G.T., 1999. Corporate Citizenship: Cultural Antecedents and Business Benefits. Journal of the Academy of Marketing Science, 27(4), 455-469.

31. Malhotra, N., 2010. Marketing Research: An Applied Orientation, 6th ed. Upper Saddle River, NJ: Prentice Hall. 
32. Maloni, J. M; Brown, M.E., 2006. Corporate Social Responsibility in the Supply Chain: An Application in the Food Industry. Journal of Business Ethics, 68, 35-52.

33. Matuszak, Ł., Różańska, E., 2017. An examination of the relationship between CSR disclosure and financial performance: The case of Polish banks. Journal of Accounting and Management Information Systems. 16(4), 522-533.

34. McGuire J.B., Sundgren A., Schneeweis T., 1988. Corporate social responsibility and firm financial performance. Academy of Management Journal, 31 (4), 854-72.

35. McWilliams, A., Siegel, D., Wright, P., 2006. Guest editors' introduction. Corporate social responsibility: Strategic implications. Journal of Management Studies, 43, 1-18.

36. Miles R.E., Snow C.C., 1978. Organizational Strategy, Structure and Process. New York: McGraw-Hill.

37. Minor D., Morgan J., 2011. CSR as reputation insurance: primum non nocere, California Management Review, 53(3), 40-59.

38. Mishra S.; Suar D., 2010. Does Corporate Social Responsibility Influence Firm Performance of Indian Companies? Journal of Business Ethics, 95, 571-601.

39. Morgan R.E., Strong C.A., 1997. Market orientation and dimensions of strategic orientation. European Journal of Marketing, 32 (11/12).

40. Nelling E., Webb E., 2009. Corporate social responsibility and financial performance: the "virtuous circle" revisited. Review of Quantitative Finance and Accounting, 32 (2), 197-209.

41. Peloza, J., 2006. Using corporate social responsibility as insurance for financial performance. California Management Review, 48, 52-72.

42. Peñaloza, L. Mish, J., 2011. The nature and processes of market co-creation in triple bottom line firms: Leveraging insights from consumer culture theory and service dominant logic. Marketing Theory, 11(1), 9-34.

43. Peters, R., Mullen, M., 2009. Some Evidence of the Cumulative Effects of Corporate Social Responsibility on Financial Performance. The Journal of Global Business Issues, 3(1), 1-14.

44. Qu R., 2009, The impact of market orientation and corporate social responsibility on firm performance. Asia Pacific Journal of Marketing and Logistics, 21(4), 570-581.

45. Saleh M.; Zulkifli N.; Muhamad R., 2011. Looking for evidence of the relationship between corporate social responsibility and corporate financial performance in an emerging market. Asia- Pacific Journal of Business Administration, 3(2), 165-190.

46. Stefańska, M.; Pilarczyk, B., 2015. Strategiczne i operacyjne znaczenie CRM-Cause Related Marketing w strategii przedsiębiorstw handlowych. Marketing i Rynek. 8. 690-698.

47. Tang, Z., Eirikur, H., Rotenberg, S., 2012. How Corporate Social Responsibility Engagement Strategy Moderates the CSR - Financial Performance Relationship. Journal of Management Studies, 49, 1274-1303.

48. Torgusa, N., O’Donohue, W., Hecker, R., 2012. Capabilities, Proactive CSR and Financial Performance in SMEs: Empirical Evidence from an Australian Manufacturing Industry Sector. Journal of Business Ethics, 109, 483-500.

49. Torgusa, N., O’Donohue, W., Hecker, R., 2013. Proactive CSR: An Empirical Analysis of the Role of its Economic, Social and Environmental Dimensions on the Association between Capabilities and Performance. Journal of Business Ethics, 115, 383-402. 
50. Venkatraman N., 1989. Strategic orientation of business enterprises: the construct, dimensionality and measurement. Management Science, 35(8), 942-962.

51. Wagner, M., 2009. Innovation and competitive advantages: from the integration of strategic aspects with social and environmental management in European firms. Business, Strategy and the Environment, 18, 291-306.

52. Wagner, M., Van Phu, N., Azomahou, T., Whermeyer, W., 2002. The relationship between the environmental and economic performance of firms: An empirical analysis of the European paper industry. Corporate Social Responsibility and Environmental Management, 9, 133-146.

53. Zaborek P., 2014. CSR and Financial Performance: The Case of Polish Small and Medium Manufacturers. International Journal of Management and Economics, 43(3), 53-73. 
